Gut. 1987. 28, 248-254

\title{
Enhanced oral bioavailability of meptazinol in cirrhosis
}

\author{
G G BIRNIE, G G THOMPSON, T MURRAY, G WATKINSON, \\ AND M J BRODIE \\ From the Clinical Pharmacology and Gastroenterology Units, Western Infirmary, Glasgow
}

SUMmARY Kinetic analysis was carried out after single intravenous $(25 \mathrm{mg})$ and oral $(200 \mathrm{mg})$ doses of the novel partial opioid agonist meptazinol (Meptid) in patients with non-cirrhotic liver disease (NCLD) and biopsy proven cirrhosis. Comparison was made with a group of patients with normal hepatic function. Elimination half-lives after the intravenous dose were slightly prolonged in the cirrhotics $(n=10 ; 4 \cdot 2 \pm 0 \cdot 6 \mathrm{~h})$ compared with the control $(\mathrm{n}=8 ; 2 \cdot 7 \pm 0 \cdot 2 \mathrm{~h}: \mathrm{p}<0 \cdot() 5)$ and NCLD $(n=8 ; 3 \cdot 2 \pm 0.5 \mathrm{~h})$ groups. There was no significant difference in meptazinol plasma clearance between the groups (cirrhotics $=72 \pm 8 \mathrm{l} / \mathrm{h} ; \mathrm{NCLD}=89 \pm 9 \mathrm{l} / \mathrm{h}$; control $=83 \pm 10 \mathrm{l} / \mathrm{h}$ ). After the oral dose, seven of 15 cirrhotic patients vomited but only one patient in each of the other groups was unable to tolerate the drug $(\mathrm{p}=0 \cdot 06)$. This may be explained by very much higher peak meptazinol concentrations in the cirrhotic $(\mathrm{n}=8 ; 184 \pm 37 \mathrm{ng} / \mathrm{ml}, \mathrm{p}<0 \cdot() 1)$ and NCLD $(\mathrm{n}=8 ; 131 \pm 38$ $\mathrm{ng} / \mathrm{ml}, \mathrm{p}<0 \cdot(05)$ patients than those of the controls $(\mathrm{n}=7 ; 53 \pm 12 \mathrm{ng} / \mathrm{ml})$ reflecting a mean four-fold and two-fold increase in oral bioavailability respectively (cirrhotics: $n=8 ; 27 \cdot 9 \pm 5 \cdot 3 \%: p<0 \cdot()(01$; NCLD: $n=7 ; 13.7 \pm 3.9 \% \quad p<0.05$; controls: $n=7 ; 6.5 \pm 1 \cdot 3 \%)$. There was no evidence of accumulation after chronic dosing with $200 \mathrm{mg}$ meptazinol four times daily for 13 doses in seven control, seven NCLD and six cirrhotic patients. There were no detectable differences in psychomotor function measured objectively using the Leeds Psychomotor Tester or subjectively by linear analogue scoring between the groups in all three parts of the study. The oral use of meptazinol in patients with chronic liver disease is associated more with the development of nausea and vomiting rather than excessive sedation. These data suggest that dosage reduction in cirrhotic patients is advisable particularly if the drug is taken by mouth.

Analgesics may precipitate episodes of portosystemic encephalopathy in patients with chronic liver disease.' This results from a combination of impairment of the hepatic and/or renal elimination mechanisms for the drug and increased cerebral sensitivity to its pharmacodynamic properties. The metabolism of many commonly used analgesics, including pethidine, ${ }^{2}$ methadone, ${ }^{3}$ paracetamol ${ }^{4}$ and pentazocine, ${ }^{5}$ is impaired in patients with hepatic cirrhosis. The elimination of morphine is only minimally reduced in such patients, "although there is evidence of increased cerebral sensitivity to the

Address for correspondence: Dr M J Brodic. (linical Pharmacology Unit. University Department of Medicine. Western Infirmatry. (jlatsgow.

Received for publication 26 Junc 1986. drug. This apparent increase in sedation may be the result of an increase in the free (unbound) fraction of the drug" or an increased density of opiate receptors in the frontal lobes and hypothalamus."

Meptazinol (Meptid) is a novel synthetic opioid analgesic which is effective in relieving pain associated with surgery, "11 trauma, ${ }^{12}$ renal colic, ${ }^{13}$ and childbirth. ${ }^{14}$ Its use is associated with less psychomotor impairment than is seen with pentazocine ${ }^{15}$ or with modest doses of ethanol." Reported side effects have been minor, but about $10 \%$ of patients experience nausea and vomiting. ${ }^{1 \%}$ After oral administration meptazinol is rapidly absorbed from the gastrointestinal tract and is subject to substantial hepatic first pass metabolism with a bioavailability of around $9 \%$ in healthy subjects." Within the liver, 
the major metabolic route is by conjugation with glucuronic acid and less than $5 \%$ of an administered dose is recovered unchanged from the urine." Elimination half-life is around two hours and the binding to plasma protein is low."

Meptazinol may be a suitable analgesic for use in patients with impaired liver function for two reasons. Firstly, hepatic conjugation is usually well maintained in liver disease $12=$ and secondly, the low protein binding of the drug ensures that circulating concentrations of free drug would not be grossly altered from normal in patients with hypoproteinaemia. The aim of this study was to assess the pharmacokinetic profile and pharmacodynamic response to meptazinol in patients with liver disease.

\section{Methods}

\section{PATIENTS}

A total of 10 patient controls, nine with non-cirrhotic liver disease (NCLD) and 15 patients with cirrhosis agreed to take part in the study. Eight of the cirrhotic patients were receiving spironolactone, but none of the other patients were on medication known to alter hepatic metabolism or liver blood flow. All gave written informed consent to their inclusion in the study, the protocol for which was approved by the Western Infirmary Ethical Committee.

The cirrhotic patients were aged between 28 and 68 years with a mean age of 53 years. All had biopsy proven hepatic cirrhosis. Eleven patients had alcoholic liver disease, two had primary biliary cirrhosis, and one each had chronic active hepatitis and primary sclerosing cholangitis. Eleven of these patients had episodes of bleeding from oesophageal varices and six had previous evidence of portosystemic encephalopathy. No patient was frankly encephalopathic on admission to the study.

The NCLD patients were aged from 24 to 81 years with a mean age of 50. The aetiology of the liver disease was proven by liver biopsy in all cases and was caused by alcohol in six, precirrhotic primary biliary cirrhosis in two and congenital hepatic fibrosis in one. This last patient was included in the NCLD group because he did not fulfil the histological criteria for the diagnosis of cirrhosis. He, however, had severe portal hypertension with large oesophageal varices. None of the patients had a history of portosystemic encephalopathy.

The control patients were aged between 21 and 65 years with a mean age of 39 years. Two patients had duodenal ulcers, four had chronic constipation and four were undergoing investigation of chronic abdominal pain. None had clinical evidence of liver disease and all had normal biochemical liver function tests.
Methods

ANALYSES

Routine liver function tests (serum albumin, bilirubin, alkaline phosphatase, gamma glutamyl transpeptidase) and serum creatinine were obtained by standard autoanalyser techniques (TECHNICON). Haemoglobin was measured using a Coulter counter.

The pharmacokinetics of meptazinol were studied after an intravenous dose of $25 \mathrm{mg}$, and a standard $200 \mathrm{mg}$ tablet given with $100 \mathrm{ml}$ water in random order, with a delay of at least two weeks between each part of the study. The patients were fasted overnight before each study day and food was allowed two hours after meptazinol administration. The oral kinetics were then repeated after the chronic administration in standard daily doses of the drug of $200 \mathrm{mg}$ four times daily $(0600,1200,1800,2200)$ for 13 doses. Venous blood samples were taken at $0 \cdot 25$, $0 \cdot 5,0 \cdot 75,1,1 \cdot 5,2,3,4,6,8,12$, and 24 hours after the single intravenous and oral doses and after the 13th dose in the chronic study. The samples were collected into glass lithium heparin tubes and centrifuged immediately. The plasma was separated and stored in glass tubes at $-20^{\circ} \mathrm{C}$. Plasma concentrations of meptazinol were determined by a high pressure liquid chromatography method using fluorescence detection. ${ }^{1923}$ All samples for each patient were run in a single batch. The lower limit of detection of meptazinol was $10 \mathrm{ng} / \mathrm{ml}$ and the coefficient of variation was $5 \%$ at $100 \mathrm{ng} / \mathrm{ml}$ and $9.9 \%$ at $10 \mathrm{ng} / \mathrm{ml}$.

\section{PHARMACODYNAMIC TESTS}

Psychomotor function was assessed immediately before the single doses and at $1,2,3,4$, and 6 hours after intravenous and oral (single and 13th chronic dose) administration of the drug using the Leeds psychomotor tester. This measures the critical flicker fusion threshold and choice reaction time. ${ }^{21}$ The choice reaction time is divided into two components: firstly, the time taken to move the hand from a switch when a light is switched on (recognition time or choice reaction time 1), and thereafter the time taken to move the appropriate switch (movement time). The total reaction time (recognition time + movement time) is referred to as the choice reaction time 2. On each occasion a mean of six critical flicker fusion thresholds and 3) choice reaction time readings were taken. During the 24 hours before the administration of meptazinol the subjects had a minimum of three practise runs on the Leeds psychomotor tester followed by three further runs to establish baseline values for each patient. The difference between the critical flicker fusion threshold or choice reaction time measurements and the patient's baseline results were meaned at each time point for 
analysis. Subjective sedation was also assessed at all time points using a $10 \mathrm{~cm}$ visual analogue scale with the end points of 'wide awake' and 'nearly asleep'.

PHARMACOKINETICS AND STATISTICAL METHODS After the intravenous meptazinol dose, the plasma concentration profiles were analysed by a two compartment model using a curve fitting technique. ${ }^{25}$ The areas under the plasma concentration/time curves (AUC) were obtained by the trapezoidal rule. Clearance was calculated as dose/AUC and volume of distribution as dose/AUC $\mathrm{x}$ KB where KB is the rate constant of the elimination phase. The half-life is calculated from the equation:

$$
\mathrm{t} 1 / 2=0 \cdot 693 / \mathrm{KB}
$$

After correcting the areas for difference in dose, the oral bioavailability was determined from the formula:-

$$
\text { Bioavailability }=\frac{\text { AUC (oral) }}{\text { AUC (intravenous) }} * 100 \%
$$

Results were expressed for illustrative purposes as means \pm the standard error of the mean unless otherwise stated.

Statistical analyses were by Kruskal Wallis nonparametric analysis of variance and Mann Whitney U-tests. The correlation coefficients were obtained using the Spearman ranking procedure.

\section{Results}

Haemoglobin and creatinine concentrations together with the standard biochemical liver function tests are shown in Table 1 . As expected evidence of impaired hepatic function was seen for both liver disease groups.

\section{MEPTAZINOL KINETICS}

The mean elimination half-life of meptazinol was significantly longer in the cirrhotic group than the controls (cirrhotic $n=10 ; 4 \cdot 2 \pm 0 \cdot 6$ h vs control $n=8$; $2 \cdot 7 \pm 0.2 \mathrm{~h}: \mathrm{p}<0.05)$ and was intermediate in the NCLD patients $(n=8 ; 3 \cdot 2 \pm 0 \cdot 5 \mathrm{~h})$ (Fig. 1$)$. There was a trend towards an increased volume of distribution in the patients with liver disease but this failed to reach statistical significance (control $=303 \pm 32$ l; $\mathrm{NCLD}=385 \pm 431$; cirrhotic $=402 \pm 361$ ). There was no differences in the total plasma clearance of meptazinol between the groups (control $=83 \pm 10 \mathrm{l} / \mathrm{h}$; $\mathrm{NCLD}=89 \pm 9 \mathrm{l} / \mathrm{h}$; cirrhotic $=72 \pm 8 \mathrm{l} / \mathrm{h}$ ). Seven of the cirrhotics, and one each of the NCLD and control patients were unable to complete the protocol because of severe nausea and vomiting after a single oral dose of the drug $\left(\chi^{2}: p=0 \cdot 06\right)$. The plasma concentration/time curves after the oral dose in those

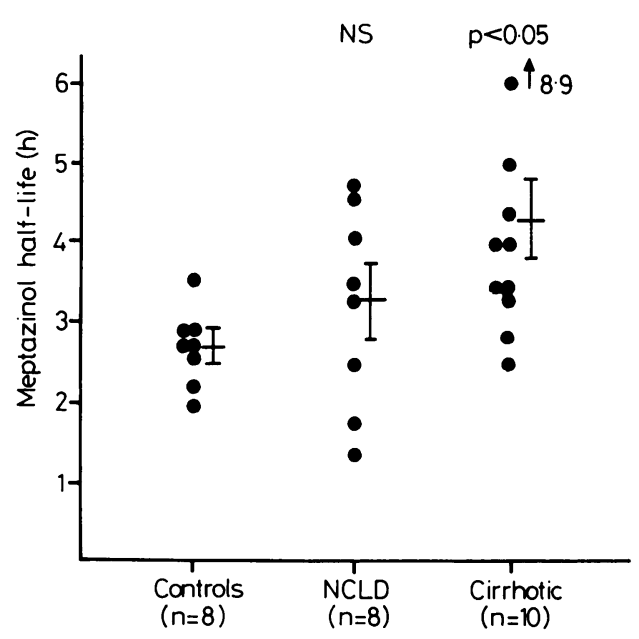

Fig. 1 Elimination halflives (mean $\pm S E M$ ) of mepatazinol after an intravenous bolus of $25 \mathrm{mg}$ in control, non-cirrhotic liver disease (NCLD) and cirrhotic patients.

patients tolerating the drug are shown in Figure 2. The peak concentration attained was much higher in the patients with liver disease (cirrhosis: $n=8$; $184 \pm 37 \mathrm{ng} / \mathrm{ml} ; \mathrm{p}<0 \cdot 01 ; \mathrm{NCLD}: \mathrm{n}=8,131 \pm 38 \mathrm{ng} / \mathrm{ml}$; $\mathrm{p}<0.05$; control: $\mathrm{n}=7,53 \pm 12 \mathrm{ng} / \mathrm{ml}$ ). The oral bioavailability of meptazinol was greatly increased in the cirrhotic patients (bioavailability $=27 \cdot 9 \pm 5 \cdot 3 \%$; $\mathrm{p}<0.001$ ) and NCLD group (bioavailability= $13.7 \pm 3.9 \% ; \mathrm{p}<0.05)$ compared with the controls (bioavailability $=6 \cdot 5 \pm 1 \cdot 3 \%$ ) [Fig. 3]. After chronic oral dosing for three days there was no significant increase in the area under the concentration time curves, time to maximum concentration, or the

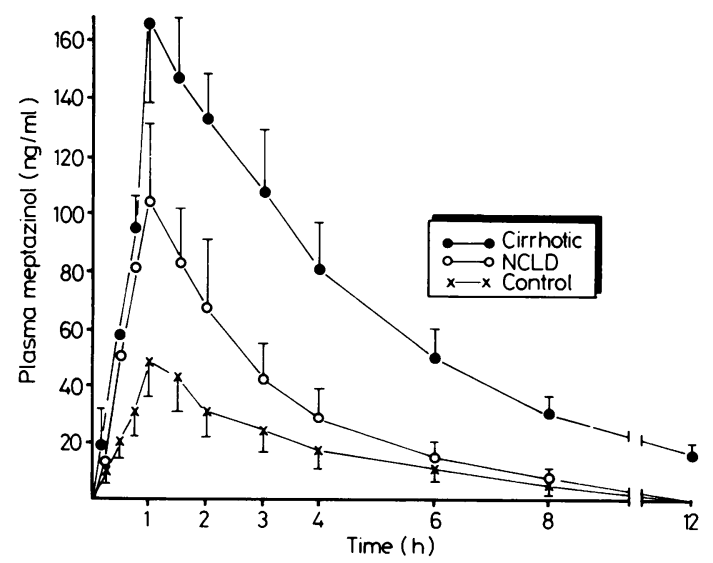

Fig. 2 Plasma concentration time curves (mean $\pm S E M$ ) following an oral dose of $200 \mathrm{mg}$ of meptazinol in control $(n=7)$, non-cirrhotic liver disease $(N C L D)(n=8)$ and cirrhotic patients $(n=8)$. 
Table 1 Standard laboratory tests (mean $\pm S E M$ ) in all control, non-cirrhotic liver disease (NCLD) and cirrhotic patients

\begin{tabular}{|c|c|c|c|c|c|c|}
\hline & $\begin{array}{l}\text { Haemoglobin } \\
(\mathrm{g} / \mathrm{l})\end{array}$ & $\begin{array}{l}\text { Bilirubin } \\
\text { (umol/l) }\end{array}$ & $\begin{array}{l}\text { Alkaline } \\
\text { phosphatase } \\
\text { (IUIl) }\end{array}$ & Albumin $(g / l)$ & $\begin{array}{l}\text { Creatinine } \\
(\mu \mathrm{mol} / \mathrm{l})\end{array}$ & $\begin{array}{l}G G T \\
(I U / l)\end{array}$ \\
\hline \multicolumn{7}{|l|}{ Control $(n=10)$} \\
\hline Mcan & $13 \cdot()$ & $11 \cdot 4$ & 50 & $41 \cdot 1$ & $80 \cdot 4$ & 21 \\
\hline SEM & $0 \cdot 3$ & $2 \cdot()$ & 10 & $0 \cdot 8$ & $5 \cdot 7$ & 4 \\
\hline \multicolumn{7}{|l|}{$\operatorname{NCLD}(n=9)$} \\
\hline Mean & $13 \cdot 6$ & $18 \cdot 3$ & 141 & $41 \cdot 7$ & 7()$\cdot 7$ & 108 \\
\hline SEM & $0 \cdot 6$ & $6 \cdot 4$ & 56 & $2 \cdot 1$ & $3 \cdot 4$ & 27 \\
\hline \multicolumn{7}{|l|}{ Cirrhotic $(n=15)$} \\
\hline Mean & $12 \cdot 1$ & $32 \cdot 6$ & 172 & $34 \cdot 5$ & 9()$\cdot 2$ & 161 \\
\hline SEM & 0.5 & $15 \cdot 4$ & 38 & $2 \cdot 0$ & $7 \cdot 1$ & 39 \\
\hline \multicolumn{7}{|l|}{ Kruskal Wallis } \\
\hline$p=$ & 0.76 & $0 .(12$ & $0 \cdot 004$ & $0 \cdot 01$ & $0 \cdot 10$ & 0.0001 \\
\hline \multicolumn{7}{|l|}{ Mann Whitncy U Tests } \\
\hline Control vs NCLD & NS & NS & NS & NS & NS & $<0 \cdot 001$ \\
\hline Control vs cirrhotic & NS & $<0 \cdot(05$ & $<0 \cdot 05$ & $<0 \cdot 01$ & NS & $<0 \cdot 001$ \\
\hline NCLD vs cirrhotic & NS & $<0 \cdot 05$ & NS & $<0.01$ & NS & NS \\
\hline
\end{tabular}

maximum concentration achieved in any of the groups compared with the values obtained after the single dose (Table 2).

PHARMACODYNAMICS

There were no significant alterations in the choice reaction time 1 , choice reaction time 2 or the critical flicker fusion threshold at any time point in any of the groups after the single intravenous and oral doses or chronic administration of meptazinol. Figure 4 shows the results of the recognition time (choice reaction time 1) during the oral, intravenous and chronic phases of the study in all patient groups. Analysis of the visual analogue scales showed no evidence of excessive sedation in any of the groups during any phase of the study. The remainder of the pharmaco- dynamic data for all three phases of the study are not shown but are available from the authors.

\section{Discussion}

This study has shown the importance of assessing the oral bioavailability of drugs in patients with liver disease, particularly those who undergo a substantial degree of first pass elimination. In cirrhotics, the clearance of meptazinol was reduced by only $13 \%$ but there was a $300 \%$ increase in the oral bioavailability of the drug. Three factors could contribute towards this later finding. Firstly, the bioavailability of meptazinol is dependent on the rate of absorption of the drug from the gastrointestinal tract. ${ }^{19}$ When absorption is rapid, the capacity of the conjugating

Table 2 Meptazinol kinetics (mean \pm SEM) after single and 13 th $200 \mathrm{mg}$ oral dose in control, non-cirrhotic liver disease (NCLD) and cirrhotic patients

\begin{tabular}{|c|c|c|c|c|c|}
\hline & \multicolumn{3}{|l|}{ Single oral dose } & \multicolumn{2}{|l|}{ Chronic dosing } \\
\hline & $\begin{array}{l}\text { Area under curve } \\
(\mathrm{ng} / \mathrm{ml} / \mathrm{h})\end{array}$ & $\begin{array}{l}\text { Maximum concent } \\
\text { ration } C P(\text { max }) \\
(\mathrm{ng} / \mathrm{ml})\end{array}$ & $\begin{array}{l}\text { Bioavailability } \\
(\%)\end{array}$ & $\begin{array}{l}\text { Area under curve } \\
(\mathrm{ng} / \mathrm{ml} / \mathrm{h})\end{array}$ & $\begin{array}{l}\text { Maximum concen- } \\
\text { tration }(P \text { (max) } \\
\text { (ng/ml) }\end{array}$ \\
\hline \multicolumn{6}{|l|}{ Controls $(n=9)$} \\
\hline Mean & 163 & 53 & 7 & 112 & 49 \\
\hline SEM & 35 & 12 & 1 & 21 & 7 \\
\hline \multicolumn{6}{|l|}{$\operatorname{NCLD}(n=8)$} \\
\hline Mean & 311 & 131 & 14 & 105 & 42 \\
\hline SEM & 78 & 38 & 4 & 17 & 5 \\
\hline \multicolumn{6}{|l|}{ Cirrhotic $(n=8)$} \\
\hline Mcan & 794 & 184 & 28 & 903 & 302 \\
\hline SEM & 148 & 37 & 5 & 247 & 92 \\
\hline \multicolumn{6}{|l|}{ Kruskal Wallis } \\
\hline$p=$ & $0 \cdot 003$ & 0.02 & 0.01 & 0.03 & $0 \cdot 06$ \\
\hline \multicolumn{6}{|l|}{ Mann Whitncy U Tests } \\
\hline Control vs NCLD & 0.09 & $0 \cdot(04$ & $0 \cdot 1$ & 0.4 & NS \\
\hline Control vs cirrhotic & 0.0001 & $0 \cdot 002$ & $0 \cdot 001$ & $0 \cdot() 2$ & NS \\
\hline NCLD $v s$ cirrhotic & 0.01 & $0 \cdot 12$ & $0 \cdot(04$ & $0 \cdot(0) 7$ & NS \\
\hline
\end{tabular}




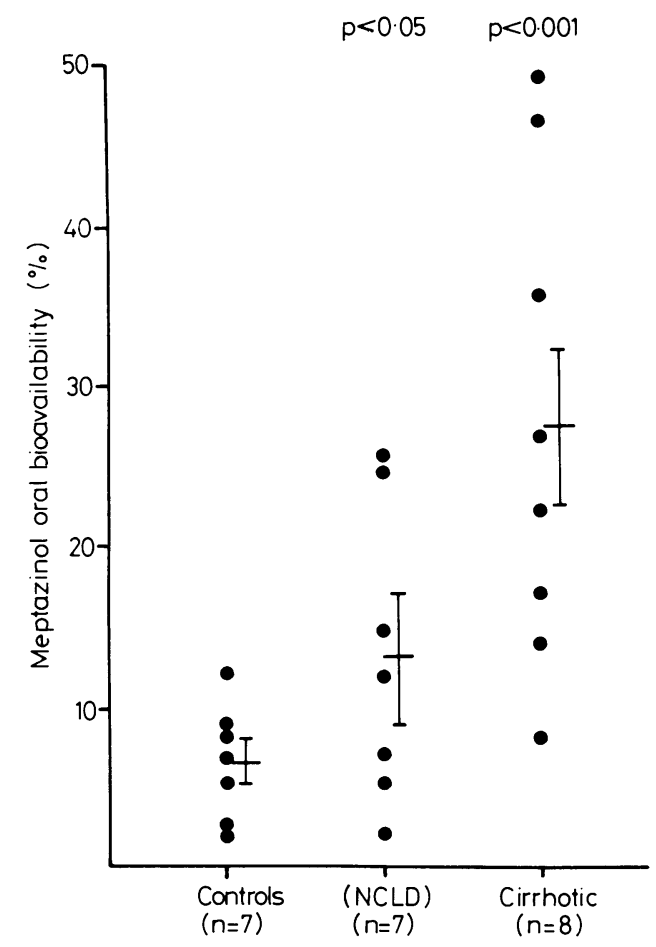

Fig. 3 Percentage oral bioavailability of meptazinol (mean $\pm S E M$ ) in control, non-cirrhotic liver disease (NCLD) and cirrhotic patients.

enzymes may be saturated resulting in an increased bioavailability. In this study the time to maximum concentration did not differ significantly between the three groups indicating that it is unlikely that there were major differences in the rates of absorption. Secondly, the ability of the hepatocytes to remove the drug from the blood may be reduced. The primary route of metabolism of meptazinol is by conjugation. The elimination of drugs which are conjugated is usually little altered in liver disease - for example, oxazepam, ${ }^{22}$ morphine," and lorazepam..$^{21}$ In contradistinction, the hepatic clearance of oxidised drugs is invariably reduced in patients with cirrhotic liver damage..$^{26}$ In the present study there was no significant reduction in the clearance of meptazinol in cirrhotics. Thirdly, the intra- and extrahepatic portosystemic shunts which occur in cirrhosis can dramatically reduce the contact of the drug with the sites of hepatic elimination with a resulting increase in the bioavailability. More than $50 \%$ of the total portal blood flow may be shunted directly into the system circulation in cirrhotics. ${ }^{27}$ In our study the majority of the cirrhotic patients studied had well established portal hypertension and $11 / 15$ had previously bled from oesophageal varices. It is probable that this last factor explains the substantial increase in oral meptazinol bioavailability in cirrhosis. Interestingly one of the patients in the NCLD group had congenital hepatic fibrosis associated with large oesophageal varices and his meptazinol bioavailability was $26 \cdot 1 \%$ which is comparable with the cirrhotic patients.

Spironolactone was the only drug which these cirrhotic patients were receiving which may alter hepatic drug metabolism. This drug is a weak inducer of hepatic oxidation in healthy volunteers, ${ }^{2 \times 24}$ and in patients with alcoholic cirrhosis. ${ }^{31}$ If spironolactone did influence meptazinol metabolism, it would be expected to reduce its oral bioavailability. Nevertheless, this may have contributed to the surprisingly small effect of severe liver disease on meptazinol clearance.

The changes in meptazinol handling in the cirrhotic patients were accompanied by an increased incidence

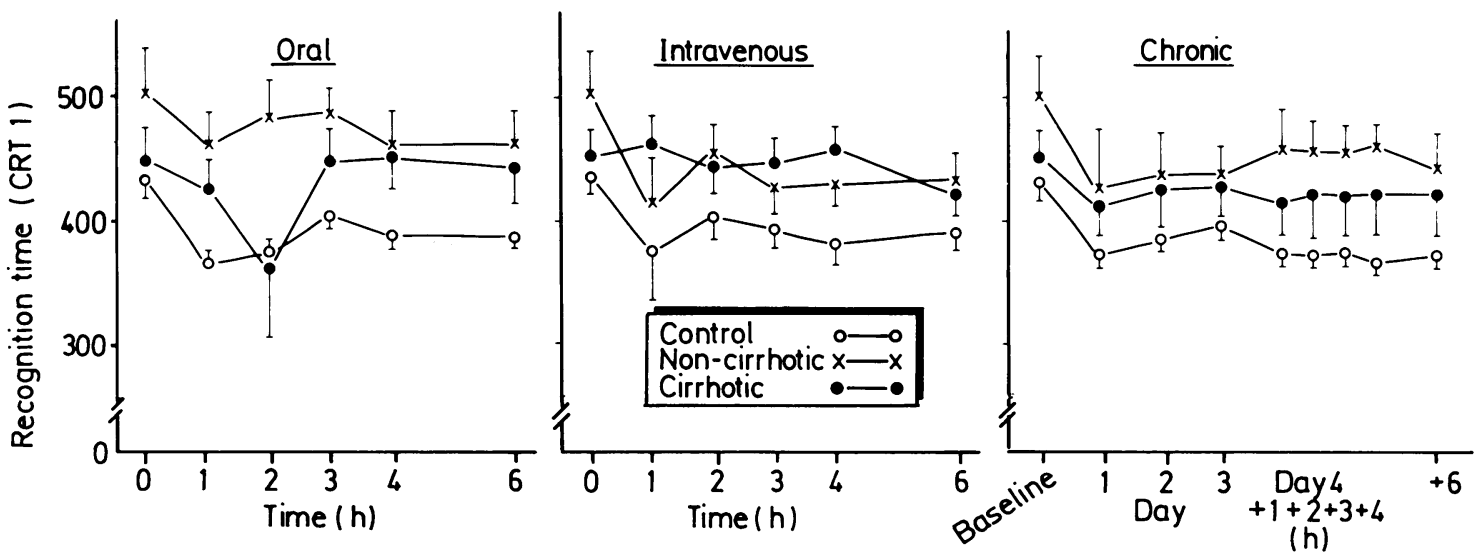

Fig. 4 Recognition time (choice reaction time 1) (CRT) in all patient groups after a single oral and intravenous dose and chronic administration of meptazinol. 
of vomiting when the drug was given orally. This occurred very shortly after administration on the upstroke of the absorption curve. Despite the high plasma concentrations by patients tolerating the drug there was no evidence of excessive sedation in any of the groups measured subjectively by sedation scoring or objectively using reaction times.

In conclusion, the oral bioavailability of meptazinol was greatly increased in patients with chronic liver disease. The drug can, however, be used in such patients without producing excessive sedation in those patients able to tolerate standard doses. In order to avoid nausea and vomiting on oral administration in patients with cirrhosis or with portal hypertension the dose should be reduced to $25-50 \%$ of that normally prescribed. If such a dose is insufficient to produce analgesia the dose and/or frequency of administration can be increased to the limits of gastrointestinal tolerance. Meptazinol dosage may not need to be altered as substantially in patients with liver disease in whom the drug is administered parenterally. Variation in oral bioavailability may also have relevance to the development of gastrointestinal intolerance to the drug in patients with normal hepatic histology.

We would like to thank Wyeth UK for financial support and, in particular, Dr David Graham for his advice in the design of the study. We are grateful to Anne Macdonald for making the pharmacodynamic measurements.

\section{References}

1 Fessel JM, Conn HO. An analysis of the causes and prevention of hepatic coma. [Abstract]. Gastroenterology 1972; 62: 191.

2 Klotz U, McHorse TS, Wilkinson GR, Schenker S. The effect of cirrhosis on the disposition and elimination of meperidine in man. Clin Pharmacol Ther 1974; 16: 667-75.

3 Novick D, Kreek MJ, Fanizza AE. Methadone disposition in maintained patients with chronic liver disease. [Abstract]. Clin Res 1980; 28: 622A.

4 Forrest JAH, Findlayson NDC, Adjepon-Yamoah KK, Prescott LF. Antipyrine, paracetamol and lignocaine elimination in chronic liver disease. $\operatorname{Br} \operatorname{Med} J 1977$; 1: 1384-7.

5 Neal EA, Meffin PJ, Gregory PB, Blaschke F. Enhanced bioavailability and decreased clearance of analgesics in patients with cirrhosis. Gastroenterology 1979; 77: 96-102.

6 Patwardhan R, Johnson R, Hoyumpa A, et al. Normal metabolism of morphine in cirrhosis. Gastroenterology 1981; 81: 1006-11.

7 Laidlaw J, Read AE, Sherlock S. Morphine tolerance in hepatic cirrhosis. Gastroenterology 1961; 40: 389-96.
8 Olsen GD, Bennett WM, Porter GA. Morphine and phenytoin binding to plasma proteins in renal and hepatic failure. Clin Pharmacol Ther 1975; 17: 677-84.

9 Zeneroli ML, Ventura E, Pinelli G, et al. Opiate receptors and beta-endorphin levels in brain areas of dogs with portal systemic encephalopathy. $J$ Hepatol 1985; 1: 619-27.

10) Paymaster NJ. Analgesia after operation. A controlled comparison of meptazinol, pentazocine and pethidine. Br J Anaesthesiol 1977; 49: 1139-45.

11 Hedges A, Turner P, Wadsworth J. A double-blind comparison of meptazinol with pethidine in postoperative pain. BrJ Anaesthesiol 1980; 52: 295-8.

12 Copeland SA. Preliminary evaluation of the use of meptazinol in trauma. Postgrad Med J 1983; 59 suppl: 64-6.

13 Coutinho A. Clinical evaluation of a new opiumantagonist analgesic. Br J Urol 1980); 6: 156-62.

14 Nicholas ADG, Robson PJ. Double-blind comparison of meptazinol and pethidine in labour. $\mathrm{Br} \mathrm{J} \mathrm{Obstet}$ Gynaecol 1982; 89: 318-22.

15 Stacher G, Steinringer H, Winklehner S, Mittelbach G, Schneider C. Effects of graded oral doses of meptazinol and pentazocine in comparison with placebo on experimentally induced pain in healthy humans. $\mathrm{Br} \mathrm{J} \mathrm{Clin}$ Pharmacol 1983; 16: 149-56.

16 Tedeschi G, Smith AT, Richens A. Effect of meptazinol and ethanol on human psychomotor performance and mood ratings. Human Toxicol 1984; 3: 37-43.

17 Davies G, Sinclair AJ, Warrington SJ, et al. Pharmacokinetics of meptazinol in man following repreated intramuscular administration. Eur J Clin Pharmacol 1982; 23: 535-8.

18 Moyes DG, Miller MT, Aldridge NJ. A comparison between meptazinol and omnopon in the relief of postoperative pain. $S$ Afr Med J 1979; 55: 865-6.

19 Norbury HM, Franklin RA, Graham DF. Pharmacokinetics of the new analgesic meptazinol, after oral intravenous administration to volunteers. Eur J Clin Pharmacol 1983; 25: 77-80.

20) Franklin RA, Aldridge A, White C de B. Studies on the metabolism of meptazinol, a new analgesic drug. $\mathrm{Br} J$ Clin Pharmacol 1976; 3: 497-502.

21 Kraus JW, Desmond PV, Marshall JP, Johnson RF, Schenker S, Wilkinson GR. Effects of aging and liver disease on disposition of lorazepam. Clin Pharmacol Ther 1978; 24: 411-9.

22 Shull HJ, Wilkinson GR, Johnson R, Schenker S. Normal disposition of oxazepam in acute viral hepatitis and cirrhosis. Ann Intern Med 1976; 84: 420-5.

23 Frost $T$. Determination of meptazinol in plasma by high performance liquid chromatography with flourescence detection. Analyst 1981; 106: 999-100().

24 Hindmarch I. Psychomotor function and psychoactive drugs. Br J Clin Pharmacol 1980; 10: 189-209.

25 Cazin J-L, Luycxx M. Determination of pharmacokinetic parameters on the Apple computer. TIPS 1984; 5: 411-3.

26 Williams RL, Koch Weser J. Drug administration in hepatic disease. N Engl J Med 1983; 26: 1616-22.

27 Groszmann R, Kotelanski B, Cohn JN, Khatri IM. Quantitation of portasystemic shunting from splenic and 
mesenteric beds in alcoholic liver disease. Am J Med 1972; 53: 715-22.

28 Taylor SA, Rawlins MD, Smith SE. Spironolactone - a weak enzyme inducer in man. J Pharm Pharmacol 1972; 24: 578-9.

29 Huffman DH, Shoeman DW, Pentikainen P, Azarnoff
DL. The effect of spironolactone on antipyrine metabolism in man. Pharmacology 1973; 10: 338-44.

30 Miguet J-P, Vuitton D, Thebault-Lucas A, Joanne C, Dhumeaux D. Spironolactone and enzyme induction in patients with alcoholic cirrhosis. Gastroenterology 1980; 78: $996-1000$. 